\section{ESTRATEGIAS COLECTIVAS PARA SOSTENER LA VIDA ANTE UN TERREMOTO. EXPERIENCIAS DESDE JUCHITÁN DE ZARAGOZA, OAXACA, MÉXICO}

Itandehui Juárez-Acevedo ${ }^{1 *}$

\section{RESUMEN}

La noche del siete de septiembre de 2017 un terremoto de magnitud 8.2 sacudió a México e impactó gravemente a Juchitán de Zaragoza. La mayoría de las familias perdieron sus casas y medios de producción, y los principales espacios comunitarios quedaron destruidos. Pese a todo, la comunidad tuvo la capacidad de organizarse y responder rápidamente, satisfaciendo las necesidades básicas y los requerimientos urgentes. A partir de una etnografía feminista realizada entre 2017 y 2018, este artículo argumenta que después de un terremoto el sostén y la reproducción inmediata de la vida se basa en las diferentes estrategias desplegadas en colectivo, pues las acciones individuales o las respuestas Estatales parecen no bastar. Así, el texto reconstruye las experiencias alrededor del terremoto, examina las principales necesidades que surgieron y analiza las creativas respuestas colectivas que las personas activaron ante la emergencia.

\section{PALABRAS CLAVES}

Terremoto, Reproducción de la vida, Estrategias colectivas, Entramados comunitarios, Juchitán de Zaragoza, México

\section{COLLECTIVE STRATEGIES TO SUSTAIN LIFE IN AN EARTHQUAKE. EXPERIENCES FROM JUCHITÁN DE ZARAGOZA, OAXACA, MÉXICO}

\section{ABSTRACT}

On September 7th, 2017, a 8.2 magnitude earthquake shook México and seriously impacted Juchitán de Zaragoza. Most of the families lost their houses and means of production, and the main community spaces were destroyed. But the community was able to organize and respond quickly, satisfying basic needs and immediate requirements. Based on feminist ethnography carried out between 2017 and 2018, this article argues that after an earthquake the support and immediate reproduction of life is based on the different strategies deployed collectively, since individual actions or State responses seem not enough. The text reconstructs the experiences around the earthquake, examines the main needs that arose and analyzes the creative collective responses that people activated in the emergency.

\section{KEYWORDS}

Earthquake, Reproduction of life, Collective strategies, Community weft, Juchitán de Zaragoza, Mexico

\author{
1. Centro de Investigaciones \\ y Estudios Superiores en \\ Antropología Social (CIESAS), \\ Unidad Pacífico Sur, Oaxaca, \\ México. \\ *Autor de correspondencia: \\ ita.juav@gmail.com \\ DOI: \\ https://doi.org/10.55467/ \\ reder.v6i1.91

\section{RECIBIDO} \\ 12 de agosto de 2021

\section{ACEPTADO} \\ 22 de noviembre de 2021

\section{PUBLICADO} \\ 1 de enero de 2022 \\ Formato cita \\ Recomendada (APA): \\ Juárez-Acevedo, I. (2022). \\ Estrategias colectivas para \\ sostener la vida ante un \\ terremoto. Experiencias \\ desde Juchitán de Zaragoza, \\ Oaxaca, México. Revista de \\ Estudios Latinoamericanos \\ sobre Reducción del Riesgo \\ de Desastres REDER, \\ 6(1), 142-155. https://doi. \\ org/10.55467/reder.v6i1.91
}

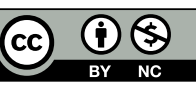

Todos los artículos publicados en REDER siguen una política de Acceso Abierto y se respaldan en una Licencia CreativeCommons Atribución-NoComercial 4.0 Internacional.

Revista de Estudios Latinoamericanos sobre Reducción del Riesgo de Desastres (REDER)

Diseño: Lupe Bezzina 


\section{INTRODUCCIÓN}

Eran las 11:49 de la noche del siete de septiembre de 2017 cuando el terremoto más intenso de los últimos 100 años en México, de magnitud 8.2, azotó el país. El municipio más afectado fue Juchitán de Zaragoza, ubicado en la región del Istmo de Tehuantepec del estado de Oaxaca (ver Figura 1). Así comenzó el "tiempo de ruptura" (Gutiérrez, 2008: 47) que trajo consigo la transformación de la vida en la comunidad.

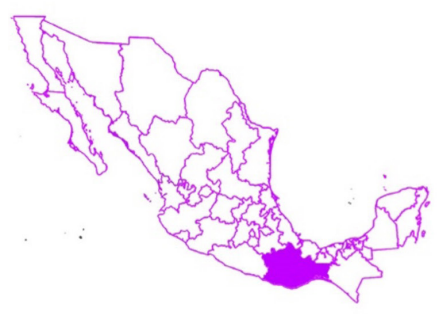

México

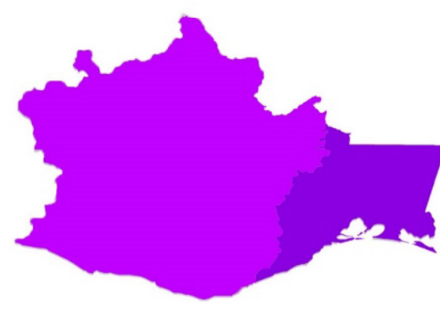

Oaxaca

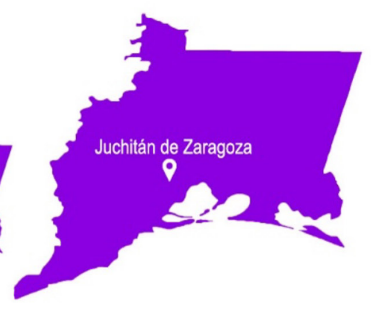

Istmo de Tehuantepec

Figura 1. Ubicación del municipio de Juchitán de Zaragoza, México Fuente: Christian Rasgado, 2022

A consecuencia del movimiento telúrico la mayoría de las personas perdieron su casa, sus medios de producción y diferentes pertenencias con valor sentimental. Los espacios comunitarios -como el palacio municipal, el hospital, los templos y el mercado- también quedaron destruidos. Esto generó un gran impacto emocional en la comunidad, la pérdida de significantes y la incertidumbre ante lo que sucedía creó una enorme preocupación y miedo por cómo sobrevivirán en dichas condiciones.

Este artículo tiene por objetivo describir y analizar las respuestas colectivas que las personas desplegaron para reproducir la vida inmediatamente después del desastre. Para ello, la investigación indaga en cómo se activan los entramados comunitarios durante los diferentes momentos del desastre, enfatizando en las estrategias desarrolladas para hacer frente a las principales necesidades que surgieron.

Al hablar de reproducción de la vida me refiero al conjunto de acciones, cuidados y relaciones por medio de las cuales la energía física, emocional y la capacidad laboral se restauran cotidianamente (Federici, 2013: 21). Los trabajos reproductivos que las mujeres realizan cada día sostienen la existencia. La alimentación, el cuidado y el descanso son, entre muchas otras, actividades necesarias para que las personas puedan vivir. Entonces, antes de cualquier tipo de producción se encuentra la reproducción: para que el trabajo "productivo" sea posible se necesita primero la revitalización de la persona que realizará ese trabajo (Federici, 2013).

Luego del terremoto el trabajo reproductivo se colectivizó y florecieron múltiples "luchas por lo común" que pueden entenderse como aquellos esfuerzos colectivos fundados en una relación social y una subjetividad de cooperación, que buscan producir, defender y mantener las condiciones que garantizan la vida colectiva (Navarro, 2015: 109; Gutiérrez, 2017: 2). Estas luchas se basaron en los entramados comunitarios que se revitalizaron en Juchitán, es decir, en las relaciones y vínculos sociales interdependientes que producen lo común como un fin compartido, a partir de una colectividad que emerge y se acompaña para reproducir la vida, material y simbólica, siguiendo la lógica del valor de uso, generando riqueza concreta y priorizando el sustento (Gutiérrez, 2017; Navarro, 2015). Estos elementos fueron los principales soportes y nutrientes de la vida concreta en tiempos de ruptura.

\section{METODOLOGÍA}

La investigación es de corte etnográfico, busca "documentar lo no-documentado de la realidad social" (Rockwell, 2009: 21) y se basa en la interacción constante y directa con las personas para acercarse a "los lenguajes y conocimientos locales" (Rockwell, 2009: 184). Partiendo de un enfoque feminista, recurro a la teoría del punto de vista y a los conocimientos situados (Haraway, 1995; Harding, 1998) como recursos epistemológicos para narrar desde el punto de vista de las mujeres. Esto no significa que no reconozca el papel que tienen los hombres en la reproducción de la vida, sin embargo, mi interés es visibilizar el trabajo y la perspectiva de las mujeres como parte de la gestión y la logística para hacer frente y responder a los desastres. 
Realicé el trabajo de campo de agosto a diciembre de 2018, sin embargo, mis visitas a Juchitán iniciaron desde septiembre de 2017, cuando asistí como voluntaria de una brigada de atención psicosocial para dar acompañamiento a las personas afectadas por el sismo. Las principales técnicas de investigación utilizadas fueron la observación participante y la entrevista a profundidad, que se complementaron con una extensa investigación documental, académica y hemerográfica.

La observación participante facilita el análisis crítico de los conceptos teóricos y permite anclarlos en la realidad concreta (Guber, 2001: 62), aplicando esta técnica acompañé a las personas en sus trabajos, festividades y descansos. Participé y documenté actividades como el $8^{\circ}$ Encuentro Nacional de Damnificados; el primer aniversario del terremoto en 2018; el $2^{\circ}$ censo realizado para evaluar los daños y diversas acciones en defensa del territorio. Al mismo tiempo, fui voluntaria en un proyecto de reconstrucción de cocinas, por eso participé continuamente en trabajos de cimentación, construcción con materiales locales como lodo y zacate, colocación de techos y elaboración de fogones.

Para fortalecer mis observaciones y la información obtenida a través de los diálogos cotidianos y espontáneos, utilicé la entrevista a profundidad que, según Restrepo, permite "comprender a detalle las percepciones de las entrevistadas o profundizar en el conocimiento de situaciones pasadas o presentes desde su perspectiva" (2007: 2). Para fines de este artículo me baso en 11 entrevistas semiestructuradas, realizadas a personas que habitan distintas Secciones de Juchitán (Ver Figura 2) ${ }^{1}$, que vivieron el momento del terremoto y cuyas casas, medios de producción 0 bienes materiales se vieron afectados.

Con el fin de generar una comprensión profunda de las respuestas colectivas que las personas desplegaron ante el terremoto, la información construida durante el trabajo de campo se codificó mediante el análisis temático que permitió crear categorías analíticas en función de las principales soluciones a las necesidades que surgieron inmediatamente después del desastre: 1) salvar vidas y rescatar cuerpos; 2) conseguir comida y satisfacer el hambre; 3) crear un techo para resguardarse; 4) garantizar la seguridad y el cuidado mutuo; 5) levantar escombros y despejar espacios.

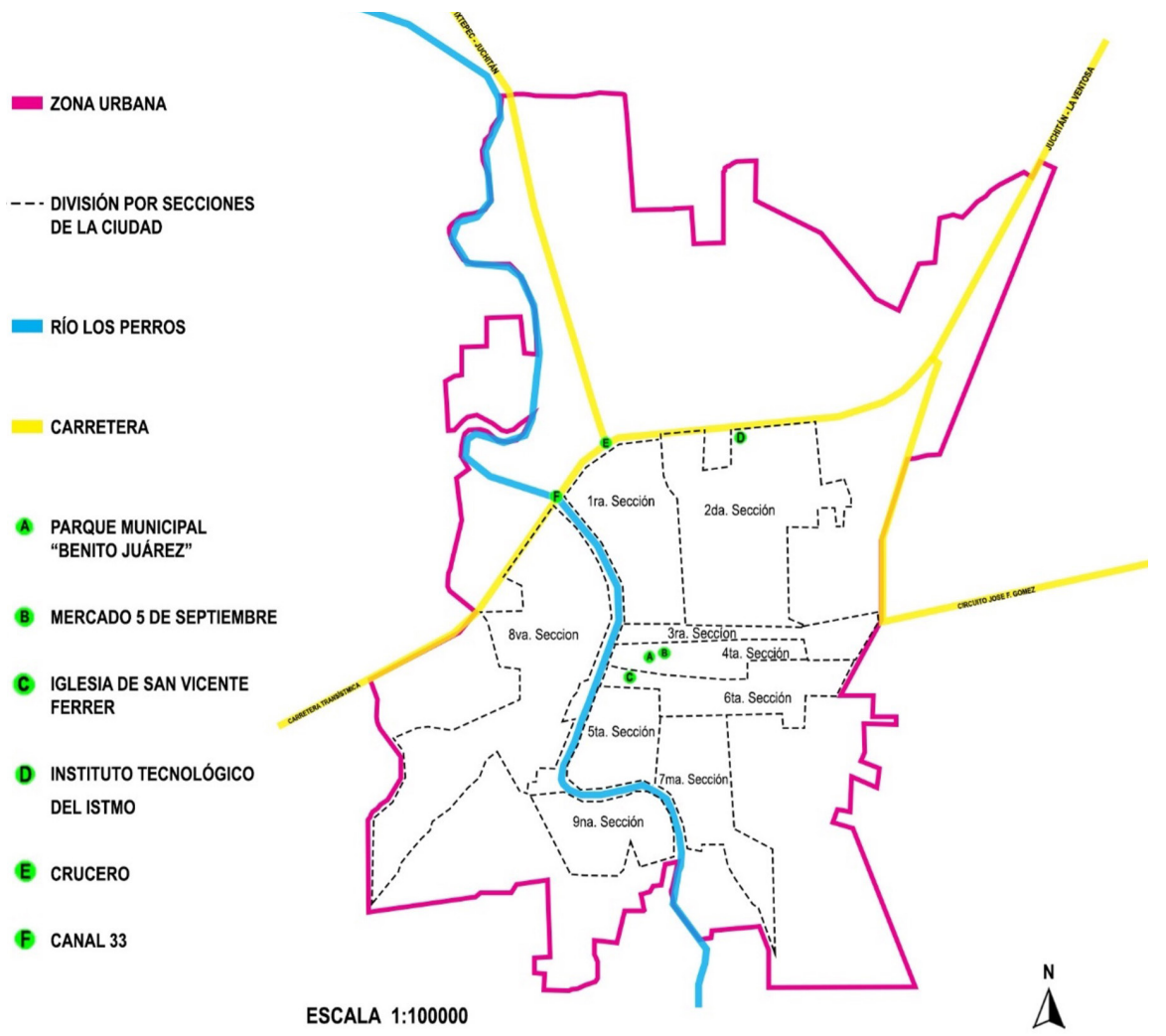

1. En adelante, para identificar las Secciones de Juchitán volver a esta figura. 


\section{"TE SIENTES NADA AL LADO DE TANTA FUERZA". NARRATIVAS DEL TERREMOTO}

Mientras sus hijos juegan en el patio, Guie'biaani' los observa desde la cocina. Ella tiene 24 años y, junto con sus hijos de 4 y 6 años, vive en Cheguigo, el barrio que abarca la Cuarta y la Octava Sección de Juchitán. La casa de Guie'biaani' es colorida. Paredes rosas, azules y blancas están adornadas con cuadros y grandes ventanas permiten que la luz entre e ilumine todo lo que hay dentro. Al levantar la mirada al techo pueden observarse algunas grietas que cruzan en diagonal y bajan por las paredes. El impacto material del terremoto está ahí, donde Guie'biaani' narra lo que pasó la noche del terremoto:

Yo estaba en el cuarto pintando. Cuando empezó el movimiento era muy leve, mi mamá jaló a uno de mis hijos y salió corriendo y gritando. Yo dije "ahorita va a pasar, tranquila", pero cuando vi que el meneíto seguía me paré rápido y agarré a mi otro hijo, que estaba durmiendo en la hamaca. Cruzamos la puerta y fue cuando empezó el jalonzote, nos íbamos a caer, pero mi mamá y un tío nos pudieron jalar. El movimiento y el sonido que surgía de la tierra era muy fuerte, ahí es donde te sientes nada al lado de tanta fuerza. Volteaba al callejón y veía cómo la barda se hacía como papel, en un momento pensé que se iba a abrir la tierra y abracé a mis hijos. Era increíble. Cuando empezó a disminuir el movimiento abrimos los ojos para ver qué había pasado, había una polvareda tremenda, el olor a gas, el agua cayéndose de las cisternas... salimos a la calle y todos los vecinos en shock, gritando, llorando, bien feo (Guie'biaani').

El siete de septiembre de 2017 la vida había transcurrido normalmente. Durante el día la rutina fue común, en la noche las personas habían terminado sus actividades y estaban en sus casas. Algunas personas terminaban de cenar mientras otras dormían o se disponían a acostarse, como $\mathrm{Na}^{2}$ Lugarda. Ella tiene 79 años y vive en la Quinta Sección, la más antigua de la comunidad. Hasta antes del terremoto, habitaba una gran casa verde de dos pisos que tenía amplias habitaciones alrededor de un patio central rodeado de gruesas columnas que formaban arcos. La noche en que inició el desastre ella se encontraba ahí junto con su nieta y su nieto:

Cuando empezó a temblar yo estaba en la hamaca y mi nieta en la cama, ella vino hacia mí pero en el trayecto le cayó un pedazo de mezcla, un ladrillo, se rompió la cabeza. "Estoy sangrando" dijo. Y yo en la desesperación me acorde que en mi buró tenía un paquete de algodón. No supe ni cómo caminé y le rasgué al algodón, le dije "así póntelo mamá...no te muevas de mí" (...). Afuera se escuchaban ruidos feos y le dije "no te salgas, no sé qué está pasando ahí afuera, no te salgas". Y el niño llorando y yo consolándolo, decía "ya va a pasar" pero en realidad pensaba "¿cuál ya va a pasar? esto ya no va a pasar". Y no sé cómo levanté los ojos, no sé ni cómo vi que una de las vigas del techo ya se estaba saliendo, y pensé "esta casa se va a venir encima de nosotros....pues ya ni modos, es el fin, ni hablar". Ya nada más me puse junto a la pared con ellos, así hasta que paró (Na Lugarda).

Para las y los juchitecos vivir un terremoto era inimaginable, el movimiento telúrico las tomó por sorpresa y cambió sus vidas de un momento a otro. Mientras la tierra se sacudía, nadie tenía claro qué hacer o cómo reaccionar. Manu, un hombre de 30 años que es profesor de primaria y vive en la Segunda Sección de Juchitán, apunta: "dicen que fueron 153 segundos, pero esos casi tres minutos parecieron una hora, una eternidad que no terminaba".

El terremoto sonaba como "un zumbido, como si hubieran alborotado un panal", y junto con los derrumbes y los gritos provocaba desesperación e incertidumbre. En cuanto el movimiento telúrico cesó las personas salieron a las calles y percibieron el impacto de lo sucedido. A partir de ese instante la vida fue otra. Los movimientos de la naturaleza "marcan nuestros ritmos, sus humores marcan nuestras festividades, sus calores y sus fríos determinan nuestras necesidades, nos da la respuesta para la reproducción de nuestra especie", sostiene Jaime Martínez (2015: 108). El siete de septiembre de 2017 el terremoto marcó un parteaguas en los ritmos y las pautas de la vida.

Mario, un profesor de 27 años que vive con su madre y su hermano en un fraccionamiento ubicado en la periferia de la ciudad, narraba el panorama que observó mientras él y su familia se dirigían a la casa de su abuela, localizada en el centro de Juchitán, para saber cómo estaban sus familiares y qué había sucedido en ese espacio:
2. "Na" es una palabra de origen zapoteco cuyo significado es "señora", en Juchitán se utiliza para referirse con respeto a las mujeres mayores o casadas. 
Cuando acabó de temblar, mi mamá, mi hermano y yo, así como estábamos, en ropa interior, con short, con playera, descalzos, como sea, así salimos a la casa de mis tías. Agarramos el carro y yo manejé. Conforme avanzamos y entre más nos acercábamos al centro veíamos más casas derrumbadas. Gente llena de tierra saliendo de los escombros, niños llorando, gente gritando, abuelitas, abuelitos... gente pidiendo ayuda, gente sangrando. $Y$ todo destruido, las casas tiradas, polvo y escombros en los patios y en las calles (...). Para ir de la casa de mis abuelitos a mi casa son 506 minutos, pero a mí se me hizo eterno porque había casas que estaban destruidas y caían a la calle y bloqueaban el paso, teníamos que buscar por dónde entrar, cómo pasar. Cuando llegamos la casa de mis abuelos estaba destruida, pero, afortunadamente, por el calor que hacía se quedaron afuera, en las hamacas, y lograron estar bien (Mario).

Según Martín Beristain, las reacciones inmediatas ante un desastre son de "ConmociónInhibición-Estupor" (2000: 9). Éstas estuvieron presentes en la población juchiteca y se acentuaron debido a que no contaban con las medidas preventivas ni con protocolos de seguridad necesarios para actuar ante el suceso. Ya que las características físicas y materiales de la comunidad, así como las experiencias previas vividas por la población influyen de forma decisiva en cómo se viven los desastres (Baez, 2017: 3; Martín Beristain, 2000: 7), éstas marcaron una pauta significativa.

Aquí estamos acostumbrados a las inundaciones, cada año lo que es mayo, junio, julio, es tiempo de lluvias, huracanes, tormentas. A veces sí se han inundado nuestras casas, calles y colonias. Y sabíamos cómo lidiar con eso, vamos a un refugio o la gente se va a su casa de dos pisos, pero nunca habíamos experimentado un sismo de esa magnitud. Fue muy fuerte y tuvimos que improvisar (Mario).

Las personas improvisaron, pero, tomando en cuenta que "las formas asociativas casi nunca consisten en novedades plenas sino que, por lo general, se suelen recuperar, conservando $y$ transformando las tradiciones locales en las cuales, quienes luchan, han sido formados y de donde casi siempre brotan sus capacidades" (Gutiérrez, 2013: 21), las estrategias colectivas que desplegaron no nacieron de la nada: evocaron y adaptaron formas de organización, de cuidado y de acción que formaban parte del bagaje experiencial de la vida comunitaria.

Entre escombros y lluvia la comunidad comenzó a organizarse para satisfacer necesidades urgentes y tareas específicas. Como el caso del terremoto en México en 1985, "la conciencia de la necesidad de movilización y organización se fue incubando desde los primeros días en que los vecinos se hicieron cargo de las tareas de rescate, (...) instalación de campamentos y albergues (...), y remoción de escombros" (Massolo, 1986: 196).

Las respuestas inmediatas siguieron una lógica colectiva centrada en preservar la vida de la población. Inesperadamente brotaron luchas por sobrevivir, en las que se podía percibir la dignidad, la autonomía y la capacidad de cooperación. La construcción de lo común y lo comunitario, como una relación social, nutrió y sostuvo la vida en momentos de crisis.

Lo común se produce, se hace entre muchos, a través de la generación y constante reproducción de una multiplicidad de tramas asociativas y relaciones sociales de colaboración que habilitan continua y constantemente la producción y el disfrute de una gran cantidad de bienes -materiales e inmateriales- de uso común. Aquellos bienes que solemos llamar "comunes" (...) no podrían ser lo que son sin las relaciones sociales que los producen. Mejor dicho, no pueden ser comprendidos plenamente al margen de las personas, de las prácticas organizativas, de los procesos de significación colectiva, de los vínculos afectivos, de las relaciones de interdependencia y reciprocidad que les dan cotidianamente forma, que producen tales bienes en calidad de comunes (Gutiérrez, Navarro y Linsalata, 2016: 8).

Ante la emergencia, las luchas y las estrategias de supervivencia que florecen permiten generar el bienestar de las personas. Los entramados comunitarios toman fuerza y se hacen visibles priorizando el cuidado mutuo mientras deviene "un tipo de subjetividad que, en tanto el sujeto se reconoce como parte de un nosotros, está dispuesto a cooperar y a sentir como propio lo que se produce en común" (Navarro, 2015: 109). 


\section{SALVAR VIDAS Y RESCATAR CUERPOS. "VOLVIMOS A SER MÁS HUMANOS"}

En cuanto el movimiento telúrico cesó las personas comenzaron a salir a los patios o a las calles. No había luz, la oscuridad envolvía los pasos entre los escombros y el crujido de las paredes que continuaban cayendo evidenciaba lo acontecido. Gritos de desesperación surgían de todos lados: quienes se encontraban atrapadas en las casas o debajo de los escombros pedían ayuda, y quienes buscaban o rescataban a alguien también gritaban.

Al mismo tiempo, por medio de los aparatos de sonido en todo Juchitán, se comenzaron a dar avisos para informar qué casas se derrumbaron, qué personas murieron y quiénes no aparecian. Fue entonces que la población notó la magnitud que el terremoto había tenido. En esas condiciones inició "la etapa de respuesta a la emergencia" (Castro y Reyes, 2006: 103) y la prioridad era preservar la vida. Entonces las acciones colectivas se dirigieron a: 1) atender a las personas heridas; 2) rescatar a las personas bajo los escombros; y 3) rescatar los cuerpos de quienes fallecieron.

\section{Las personas heridas}

Muchas personas tenían golpes y lesiones graves: se lastimaron al tratar de cubrirse 0 al intentar escapar rápidamente. Los techos y las paredes se desplomaron sobre su cuerpo y les causaron daños inmediatos. Brindarles atención médica fue una necesidad central.

Andando en la calle era normal ver personas sangrando de la cabeza, llenas de tierra y con la ropa rota y sucia. A la gente no le importaba verse así sino estar viva. Quienes teníamos material de curación a la mano lo sacamos y se lo dimos a quien veíamos mal. Luego la gente comenzó a reunir medicina para el dolor, para desinflamar, gasas y alcohol, lo que tuvieran. Lamentablemente no era fácil conseguir mucho material porque la mayoría se quedó debajo de la casa (Bere).

Las personas que tenían heridas leves se limpiaban con agua y seguían ayudando. Quienes se lastimaron las piernas y no podían caminar se mantenían sentadas en lugares despejados para no moverse. Al mismo tiempo, las y los médicos, enfermeros o estudiantes -de disciplinas similares- de la comunidad comenzaron a brindar atención en las calles, sin embargo, no les era posible responder a todas las urgencias porque había una gran cantidad de personas lastimadas, así que priorizaban a quienes tenían lesiones graves.

Mientras se brindaba atención médica en las calles, por medio de los aparatos de sonido se solicitaba voluntariado para apoyar en el Hospital General "Dr. Macedonio Benitez Fuentes", donde la realidad era alarmante también. Casi la mitad del edificio se había derrumbado y el resto estaba dañado significativamente, la llegada de personas lesionadas iba en aumento y la atención era urgente. Sin embargo, ya que el servicio de salud jamás previó las medidas necesarias en caso de una emergencia, el Hospital no contaba con insumos, personal ni condiciones adecuadas para cubrir la demanda y actuar ante el desastre. De hecho, 15 personas que llegaron con bajos signos vitales en búsqueda de atención médica no sobrevivieron (Pérez, 2017).

En el hospital todo era un caos. Como no había luz las personas alumbraban con la lámpara de su celular. Los pacientes estaban en el patio, las operaciones se hacían ahí. Había mujeres que estaban dando a luz en ese momento y como hacía mucho aire todo estaba sucio, no había condiciones apropiadas. Una señora tenía media cara rota, le tenían que coser la piel y se la cosieron ahí, con todo sucio. Los heridos se sentaban en el piso, ahí tenían que esperar porque no había suficientes doctores ni enfermeras. Los niños no paraban de llorar, gritaban del dolor o del miedo. Y no había material para seguir atendiendo, llegó un rato en que ya no se pudo hacer nada porque no tenían ni el equipo ni el medicamento. No estaban preparados, todo eso fue negligencia (Guie'biaani').

La atención fue inadecuada, sin planes de gestión de riesgo el hospital no fue suficiente para atender a las y los heridos. Las mismas personas se brindaban los primeros auxilios y se aseguraban de que los daños y las lesiones no resultaran mortales. Con el paso de los días llegaron brigadas médicas con el fin de asistir a quien lo necesitara, como el Contingente Internacional de Médicos Especializados en el Enfrentamiento a Desastres y Graves Epidemias Henry Reeve, y su apoyo fue fundamental. 


\section{El rescate inmediato}

Cecilia Castro y Luisa Reyes (2006: 109) sostienen que, en los desastres, "la mayoría de las personas que son rescatadas vivas (...) reciben la ayuda de personas cercanas al evento (...) que tuvieron una capacidad de autoayuda (...). Mujeres y hombres actúan, estén preparados o no, antes de que se establezca un control gubernamental". En cuanto terminó el terremoto comenzaron las visitas a las casas contiguas preguntando si la familia estaba bien, si faltaba alguien o si precisaban ayuda. Rescatar a las personas que quedaron atrapadas fue otra emergencia.

Parte de la casa de la vecina se derrumbó, el portón y la barda se habían caído y nadie salía. Junto con mi tío comenzamos a quitar los escombros que habían quedado en la puerta. Ellos gritaban pidiendo auxilio y nosotros les gritábamos que no se movieran, que mantuvieran la calma en lo que lográbamos despejar para que pudieran salir. Mi tío entró primero y logró sacarlos uno por uno, con cuidado. La señora estaba en shock y temblaba, como que su mente no asimilaba...mucha gente estaba así (Guie'biaani').

El peligro motivó la solidaridad, al experimentar la necesidad de sobrevivencia de manera conjunta las personas comprendieron que dependían entre sí y el apoyo para trabajos de rescate surgió rápidamente. La población se organizó y reunió herramientas como palas, picos, carretillas, mecates y material para dar sostén a los techos. En minutos, se movilizaron para auxiliar y garantizar el bienestar físico de quienes estaban cerca, principalmente vecinos y familiares.

No sé ni de donde salieron dos hombres en la ventana. "¿Necesita ayuda?" me dijeron. "Sí", contesté yo. "Pérece, deme la llave de su zaguán" me dijeron (...). Siempre las dejo en el buró, pero no las encontré. Alumbré con la luz de mi bastón y cuando las vi mi nieta las levantó y se las dio. Pero no pudieron abrir porque afuera estaba lleno de escombros de la casa que se había caído, se cayó hacia afuera, no hacia dentro. Cuando logramos salir vimos que todos andaban dando auxilio. Entonces dijeron "fulanita no ha salido, menganita no ha salido". En una casa de aquí junto murieron dos personas, se les cayó toda la casa encima, los aplastó la viga. Todos empezaron a maniobrar y como a las 4 de la mañana los sacaron (Na Lugarda).

El rescate estaba a cargo de las personas de la misma comunidad, de quienes trabajaban en protección civil y de policías municipales. El cuidado de la vida se colectivizó porque las acciones individuales no alcanzaban a cubrir las necesidades. Como señala Guie'biaani', "todos salvaban a todos (...). Hubo quienes tuvieron que dar machetazos a las puertas que eran de tabla, las quebraron para que la gente saliera, y las puertas de metal las cortaron con cuidado".

La precaución al maniobrar también era primordial porque un movimiento impreciso podía provocar que la vivienda colapsara y se derrumbara. "Por acá una señora quedó atrapada y los vecinos se organizaron para sacarla, con palos y cuerdas sostenían la loza que estaba a punto de caerse. Gracias a Dios la sacaron con vida, aunque se lastimó una pierna. Los vecinos no esperaron, se arriesgaron" (Na Irma).

\section{Las muertes de esa noche}

De acuerdo con las autoridades, el terremoto dejó un total de 78 muertes en Oaxaca, de las cuales 37 eran de Juchitán (Ferri, 2017; Milenio, 2017; Oficina del Coordinador Residente de las Naciones Unidas, 2017). Sin embargo, las cifras del conteo "oficial" se quedaron cortas comparadas a la realidad porque "sólo contaron a los muertos que se veían, a quienes murieron en las calles o casi afuera de su casa. Pero a quienes se quedaron bajo los escombros y sacaron sus cuerpos después de que habían hecho el conteo ya no" (Manu). A pesar de que no existe un número exacto, el conteo realizado por la comunidad concluyó que fueron entre 90 y 110 personas fallecidas.

La mayoría de las muertes estuvieron causadas por los derrumbes de las viviendas, porque los techos o las paredes de las casas se desplomaron encima y les fue imposible soportar ese peso. Los cuerpos de estas personas fueron rescatados más tarde, cuando las y los vecinos o familiares se daban cuenta de que no salían de las casas y al llamar nadie respondía, o cuando alguien que sobrevivió gritaba pidiendo auxilio. 
En la esquina del puente me tocó ver a la señora que quedó atrapada con la mitad del cuerpo afuera y la mitad adentro (...). En la Sexta [Sección] el esposo y las dos hijas de una muchacha murieron, ella decía que estaban acostados en la hamaca y de repente despiertan y todo se les viene encima, sus hijas murieron al instante, una de cuatro años y la otra de meses, él todavía estuvo agonizando, alcanzó a decirles palabras, se despidió. Ella tuvo que salir a pedir ayuda. Fue horrible (Guie'biaani').

Otras personas también fallecieron en las calles y callejones de Juchitán. Como las réplicas del terremoto siguieron, las construcciones dañadas que aún estaban de pie continuaron derrumbándose, era incierto saber cómo y en qué momento caerian. Los patios y los lugares despejados y sin construcciones eran los espacios seguros, pero no todas las personas pudieron llegar a ellos.

Fue triste. Una muchacha de allá adelantito se murió junto con su hijo, pero su casa no cayó encima de ellos. Como no tenían patio salieron de su casa y querían irse a otro lado, y cuando venían en un callejón la barda de otra casa les cayó encima. Los dos murieron, la mamá y el hijo (Na Amelia).

La noche transcurrió así, entre réplicas, lluvia y oscuridad "todo era miedo, pánico, muertes por aquí, muertes por allá. Por todos lados había gente tirada" (Na Irma). Las personas también fallecieron en espacios comunitarios. En el palacio municipal, por ejemplo, dos policías se encontraban de guardia y no pudieron salvarse porque la construcción se desplomó rápidamente, su rescate comenzó al amanecer.

La población se encargó del rescate de los cuerpos un par de días más. Por otro lado, según el Fondo de las Naciones Unidas para la Infancia (UNICEF), por parte del gobierno "la organización de actividades de búsqueda y rescate (...) concluyeron oficialmente el 5 de octubre de 2017" (2018: 7). Los días posteriores se vivieron con temor e incertidumbre ante lo que sucedería, las personas estaban tristes y angustiadas, viviendo sus procesos de duelo. Sin embargo, ante las necesidades existentes, seguian nutriendo el cuidado mutuo y actuando en conjunto.

"Juchitán se levantó. Entre vecinos se echaban la mano, había solidaridad y eso ya se había perdido. Volvimos a ser más humanos, si tenías alguna diferencia con algún vecino en ese momento se te olvidaba e ibas a ayudar" explica Mario. En "tiempos de ruptura de lo cotidiano" (Gutiérrez, 2008: 47), las prácticas colectivas y la ayuda mutua son centrales para salvar vidas y cuidarse entre sí. El terremoto sacudió todo, movió la tierra y las casas, pero también la forma en que las personas se relacionaban.

\section{CONSEGUIR COMIDA Y SATISFACER EL HAMBRE}

Al amanecer, los rayos del sol iluminaron las construcciones derrumbadas, los techos en el suelo y los morillos y las varillas deformadas. Los límites físicos se desdibujaron mientras dejaban ver las dinámicas cotidianas que existen alrededor de la búsqueda de bienestar. Fue entonces que conseguir comida se volvió prioridad. Las personas tenían hambre y no contaban con suficiente despensa 0 alimentos imperecederos.

Imagínate, sin luz, sin agua, sin nada. La comida escaseó y las tiendas estaban vacías. Recuerdo que a las 12 de la noche fue el temblor y a las ocho de la mañana mi mamá me dijo "no tenemos nada, no hay despensa, nada para comer". Solamente teníamos tortilla almacenada. "Voy a ir a la tienda, voy a traer un casillero de huevo o lo que consiga, con lo que consiga hacemos algo" le dije. ¿Apoco había? No, ni agua, ni sopa, ni nada. Las tiendas cerraron porque ya se les había acabado todo, ya no había dónde comprar (...). El agua vino hasta el tercer día. Los aguadores empezaron a escasear, no se daban abasto. Todo el mundo sufría porque no tenían agua. Nadie se lo esperaban, todo el mundo se confío, la vida normal es al día, al día. Entonces la vimos dura (Heidi).

La escasez orientaba las acciones. Las personas que lograron comprar alimentos en cantidades suficientes los guardaban y los administraban con cuidado "por si se ocupaba después, porque sabían que todo se acabaría", como dice Na Manuela. Por la misma razón, quienes se dedicaban a producir queso, huevos criollos o carne, dejaron de comerciar: vender la comida no era opción, preferían consumirla. Conseguir qué comer o qué tomar no era fácil, las horas transcurrían 
una tras otra con la urgencia latente. Sin embargo, gracias a los medios de comunicación y a las redes sociales, el impacto del terremoto en Juchitán ya era noticia estatal y nacional, así que comenzaron a llegar víveres y fue más sencillo satisfacer el hambre.

\section{La llegada de los víveres}

Los víveres llegaban por vía terrestre o aérea y eran enviados, principalmente, por personas originarias de Juchitán que radicaban en otro lugar o por personas de la sociedad civil que se organizaron desde diversas geografías. Por otro lado, según la UNICEF, "las diferentes instancias de gobierno coordinaron a través del Sistema Nacional para el Desarrollo Integral de la Familia (DIF) la distribución de comida (...) a las poblaciones necesitadas" (2018: 7).

Botellas de agua y bolsas de arroz, de lentejas o de pasta, llegaban junto con alimentos enlatados, algunas verduras y cereales. Los víveres eran repartidos entre las y los juchitecos que, en realidad, no estaban acostumbrados a comer esos alimentos. Sin embargo, dadas las circunstancias y las necesidades, "no había de otra", las personas tuvieron que adaptarse.

Cuando empezaron a llegar los primeros víveres la veíamos muy difícil, pero conforme pasó el tiempo nos fuimos adaptando al medio. Nos repartían despensas que venían de todas partes y la gente estaba agradecida (...). No estábamos acostumbrados a comer de lata, la gente aquí no come así. Aquí en el Istmo todo es fresco, todo es carne, todo es pescado. Y en cambio ¿qué comíamos? sopas, arroz... nos repartían sardinas, nos repartían atún... en nuestra vida habíamos comido atún enlatado nosotros, pero lo comimos. Ese día todos lo comieron porque no había de otra, no había ni cómo poner un frijol (Heidi y Na Lugarda).

Los víveres llegaron en mayor cantidad con el paso de los días. Al mismo tiempo, las y los habitantes improvisaron cocinas y fogones, rescataron de entre los escombros parrillas, trastes, mesas y sillas, y utilizaban las licuadoras o los refrigeradores que aún servían. La reproducción de la vida se cimentó en las tramas comunitarias existentes, es decir, en las relaciones sociales que permitían colectivizar medios y recursos con el fin de buscar el bien común. Al respecto, Raquel Gutiérrez explica:

Las tramas comunitarias nunca son algo dado o meramente heredado, sino que son creaciones colectivas plásticas y diversas, son ensayos reiterados de producción de vínculos estables y capaces de dotarse de y conservar, ajustando y equilibrando, formas de autorregulación que sostengan su existencia en el tiempo (2017: 16).

Ante la emergencia comenzaron a formarse pequeños grupos siguiendo una lógica espacial y vecinal. Las y los juchitecos que compartían patios o que vivían cerca se organizaron para conseguir insumos y generar las condiciones para preparar alimentos. Fue así como, poco a poco, en el territorio juchiteco surgieron más de 100 cocinas comunitarias. En éstas, las mujeres dedicaron una gran cantidad de tiempo, energía y saberes:

Las cocinas comunitarias tuvieron un potencial notable para sostener la vida; basadas en el trabajo de las juchitecas permitieron satisfacer el hambre y optimizar el uso de los recursos (...), producían común mientras revitalizaban las tramas y los vínculos comunitarios. (...) Ellas se encargaron de la mayor parte del "ciclo del trabajo alimenticio", conformado por labores que suelen pasar inadvertidas pero cuya relevancia es central: 1) coordinar las tareas; 2) gestionar los víveres; 3) planear la comida; 4) elaborar la comida; 5) repartir los alimentos; y 6) limpiar el material y la cocina (Juárez-Acevedo, 2020: 103-104).

\section{CREAR UN TECHO PARA RESGUARDARSE}

A nivel nacional el municipio que más afectaciones tuvo en las viviendas a causa del terremoto fue Juchitán, con un total de 15,087 casas dañadas (García, Méndez, Franco y Olmedo, 2019). De un momento a otro las personas perdieron sus hogares, eso fue un golpe fatal porque con ellos gran parte de su vida se desmoronó. Las construcciones no son sólo un conjunto de elementos físicos, es decir, de adobe, morillos o concreto, sino también simbólicos y afectivos: contienen fragmentos de vida, emociones y sentidos que forman parte de lo que las personas son.

La vida cotidiana es una sucesión de certezas, de elementos que por repetidos son incuestionables. Ella gira y se organiza alrededor de "la casa", lugar de encuentro, de llegada y de salida de los miembros que componen la unidad doméstica o la familia (...). La 
casa se convierte en el referente de las prácticas de sus moradores (...), es el lugar desde el que se interpreta el mundo exterior (Reguillo, 2005: 264, 268).

La casa materializa la historia de las personas, simboliza años de trabajo, sueños e ilusiones. Al respecto, Heidi relata: "la casa de mi mamá quedó destruida (...). Cuando la vinieron a evaluar dijeron que ya no tenía solución, que se tenía que tirar. Mi mamá no quería ipues imagínate, su vida en esos dos pisos!". El significado de las construcciones se hizo latente en cuanto éstas se derrumbaron junto con muchos de los referentes emotivos que acogían.

El espacio es un elemento primordial de la interacción humana, "se carga de afectividad y significado (...). Los individuos actúan y piensan ubicados siempre en un espacio y tiempo" (Tamayo, 2006: 27). Cuando las viviendas se derrumbaron, surgieron cambios en la forma de vivir, en la manera de hacer las cosas, de pensar y de trabajar. En varias ocasiones, mientras bordaba en su bastidor, Heidi explicaba:

Las casas de tejavana que la gente adoraba porque eran de la abuela o del bisabuelo, son casas que no querían remodelar porque eran antigüedades o recuerdos. Ahora todas se cayeron junto con los recuerdos y las historias. Muchas personas murieron de tristeza, sobre todo las personas mayores. Cuando se les cayó su casa también se cayó parte de la vida, se les cayó aquello por lo que habían trabajado mucho tiempo (Heidi).

Sin embargo, pese a que las personas se encontraban devastadas por las pérdidas y los daños ocurridos, tanto materiales como afectivos, tenían que buscar soluciones para las dificultades que continuaban surgiendo, la vida lo requería.

\section{Soluciones inmediatas}

Minutos después del terremoto comenzó una intensa lluvia, situación completamente desfavorable para la población, que en esos momentos se encontraba a la intemperie. Quienes pudieron se resguardaron bajo techos de láminas, algunas personas colocaron lonas que tenían a la mano y otras se quedaron bajo el agua mientras esperaban que amaneciera.

Luego vino la lluvia, estábamos sentados, pero alzando los pies para que no nos tocara, no dormimos toda la noche (...). Al otro día también llovió muy feo, cayó una tormenta eléctrica y se fue la luz. Temblaba, llovía, los truenos, el aire, todo mundo pensaba que ya era el fin del mundo. $Y$ después de la tormenta no llegó la calma, al contrario, estuvo peor lo que nos pasó. Comenzó un aire horrible, se llevó todas las lonas y andábamos buscando la forma de instalarnos. Mucha gente estaba a la intemperie, quienes no tenían casa se refugiaban con el vecino, ya que pasaba el aire, reinstalaban su campamento (Na Asunción).

"La naturaleza también caracteriza los procesos de trabajo necesarios para la reproducción de los seres humanos" señala Martínez (2010: 158). Ante la necesidad de tener un techo para protegerse, las personas enfocaron el trabajo en conseguir lonas o plásticos que les ayudaran a cubrirse de la lluvia, del viento o del sol. "En el terreno pusimos dos lonas que donaron unos vecinos, las amarraron de los árboles. Pero estábamos parados porque no había donde acostarse, cuando no llovía nos sentábamos en las sillas. Así estuvimos como una semana" explica Na Elsa.

Al principio las personas se refugiaron en espacios amplios, como patios y callejones que adecuaron con el material que tenían a la mano y que pudieron rescatar, también utilizaban corredores o casas que no resultaron dañadas. Con el paso del tiempo llegó el material necesario para comenzar a construir campamentos en las calles.

Cuando llegaron las lonas y las carpas fuimos a pedir algunas, era difícil que les dieran a todos porque no alcanzaban. Los hombres se pusieron a trabajar y las levantaron, las agarraron de los postes que estaban bien. Ahí nos dormíamos, en sillas o en lo que se pudiera, y los niños... pues como pudiéramos acomodarlos. Ahí nos quedamos a dormir mucho tiempo, nadie tenía casa y no teníamos otros lugares (Na Lugarda).

Levantar campamentos no fue el único camino. Los albergues implementados por la misma comunidad, por personas voluntarias o por el gobierno nacional, también fueron una opción viable ante la necesidad de resguardarse durante la noche. Éstos estaban ubicados en diferentes puntos de Juchitán, como escuelas, canchas de futbol o en construcciones que no resultaron dañadas. 
Hay mucha gente que estaba en sus casas de día y en la noche, como no tenía donde quedarse, donde acostarse, se fueron a los albergues (...). Ahí les dieron una carpa (...). Lo bueno es que los levantaron luego, dos o tres días después ya había varios y la gente iba ahí para asegurarse (Heidi).

Según el reporte de la Oficina del Coordinador Residente de las Naciones Unidas (2017), después del terremoto el gobierno Nacional estableció 28 refugios temporales que albergaron a 5,480 personas. Sin embargo, existe discrepancia en los datos pues, tal y como refieren algunas de las personas entrevistadas y notas de prensa, los albergues creados por el Estado fueron casi inexistentes (Bessi y Navarro, 2017: 2). En cambio, existieron más albergues independientes, organizados a partir de la respuesta comunitaria. Lupita, una niña de ocho años, relata su experiencia al asistir a uno de ellos:

Yo estuve en un albergue en la colonia Las Palmas. Ahí nos dormíamos porque nuestra casa no servía. Estaba un poco lleno. Adentro había un doctor atendiendo por si se enfermaba la gente (...). También había un niño que fue solito porque su mamá se murió el día del terremoto, él vivía ahí. Pero nosotros nada más íbamos a dormir (Lupita).

El cupo de los albergues variaba según las condiciones físicas y materiales con que contaran, pero la mayoría recibía entre 15 y 40 personas. Aunque estos espacios fueron una solución para protegerse de las inclemencias del clima, según la UNICEF, tenían "escasez de baños portátiles y de medidas de seguridad y privacidad adecuadas, lo que generó múltiples incomodidades particularmente a las niñas y las mujeres" (2018: 5). Por eso la mayoría eran utilizados sólo para dormir, durante el día las personas preferían estar en lugares conocidos.

\section{GARANTIZAR LA SEGURIDAD Y EL CUIDADO MUTUO}

Mientras los días transcurrían solucionando emergencias, las noches daban pie a otras dinámicas: "en las noches nos turnábamos o de plano nadie dormía. En el día veías a gente durmiendo, pero en la noche todos estaban despiertos porque la gente tenía miedo" (Heidi). El miedo era causado por las réplicas que continuaban, pero también por el aumento de asaltos y robos que incrementaban cuando la oscuridad llegaba. "No había pasado ni una hora del terremoto y empezaron a robar. Los ladrones entraron a tiendas, pero también a las casas cuando vieron que se quedaron vacías porque la gente salió a ayudar" (Heidi). Por eso el miedo y la inseguridad estaban presentes ante el peligro.

Dos días tenía el terremoto y ya anunciaban de noche que tuviera uno cuidado, que andaban robando. "No se duerman...ya anda un carro negro, un carro blanco con personas adentro, por favor no se duerman porque algo traman o algo van a hacer", anunciaba una bocina, anunciaba la otra. ¡Ay no! la desesperación, así nos desvelábamos (Xunaxi).

Las personas no podían descansar con tranquilidad, se encontraban en un estado de alerta constante. La seguridad era un asunto relevante. Entonces surgieron formas de organización que privilegiaban el cuidado colectivo, las personas se coordinaron y formaron grupos de cuatro o cinco hombres cuya función era cuidar a las y los vecinos durante las noches.

Mi esposo era del equipo de guardia, toda la noche nos cuidaba y en la mañana trataba de descasar un poco. Sonaban disparos y andaban robando (...). Por eso se hicieron grupos que cuidaran en las entradas de los callejones, para que vieran, porque puro de noche robaban. Y se escuchaba "ahí va uno, va de aquel lado", los anunciaban en los aparatos de sonido para que escuchara toda la gente, y más tenso todo (Xunaxi).

Las guardias dependían del número de hombres que se encontraran en el vecindario, pero trataban de turnarse para que pudieran descansar. Estas estrategias de cuidado colectivo mantuvieron a salvo a las familias y funcionaron bien. "Los hombres cuidaban. Hacian grupos de guardia y los que quisieron aprovecharse se llevaron un chasco, los agarraron (...). Otros nada más andaban viendo para aprovecharse, pero los corrieron. Todo el pueblo estuvo alerta, todo el pueblo" (Na Lugarda).

Las guardias duraron de dos a tres semanas, luego disminuyeron poco a poco. Sin embargo, es innegable que la seguridad estuvo a cargo de la misma comunidad, la organización fue interna 
y espontánea. Privilegiar el cuidado y la reciprocidad tuvo sentido para poder defender, sostener y preservar la vida.

\section{LEVANTAR ESCOMBROS Y DESPEJAR ESPACIOS}

Durante la mañana y la tarde del día posterior al terremoto, la población se coordinó para apoyar en el levantamiento de escombros y otras actividades. También llegaron brigadas de voluntariado o personal de Protección Civil, de todas las edades y provenientes de múltiples geografías.

En la mañana los constructores decidimos organizarnos y abrir las calles de Juchitán, éramos como 50 personas, trabajadores, albañiles, electricistas (...). Nos organizamos y fuimos a cortar cables de luz que estaban ocasionando cortos, abrimos las calles para que pudiera haber circulación (...). Como no estábamos preparados para eso lo hacíamos todo a mano, con lo que tuviéramos. Eso fue el primer día, inmediatamente en el momento de la emergencia (...). Luego organizamos una brigada que se llamaba "descalzo". Nos pusimos en comunicación y recibimos gente de todos lados, del norte, del sur, gente solidaria que quería ayudar. El humanismo los hizo llegar hasta donde estábamos (Óscar).

La experiencia de Óscar refleja cómo lo comunitario es una relación social que se basa en la cooperación y la responsabilidad (Federici 2013: 255; Gutiérrez 2017: 10). Ante las emergencias surgidas después del terremoto, los vínculos entre las personas, de la misma comunidad o ajenas a ella, se revitalizaron para posibilitar el bienestar colectivo y mejorar las condiciones físicas y materiales.

Según los reportes del Gobierno Estatal, en Juchitán se encontraban más de 800 mil personas damnificadas (Oficina del Coordinador Residente de las Naciones Unidas, 2017). Por eso se requería ayuda inmediata. Había varias urgencias, pero, sin duda alguna, terminar de derrumbar las construcciones para evitar accidentes y limpiar las calles más transitadas eran tareas fundamentales.

Para despejar las calles y quitar los escombros las personas utilizaban los medios y las herramientas con las que contaban. Hombres y mujeres con palas y picos trabajaban en equipo para quitar ladrillos, pedazos de cemento y adobe, levantar las vigas y acarrear la tierra. No obstante, había bloques de concreto más grandes que era difícil levantar sólo con la fuerza corporal.

No se lograban levantar los restos del palacio y las losas de las casas solamente con las manos. No había muchas máquinas, pero todos ayudaron con lo que tenían. Por ejemplo, mi esposo tiene un primo que es ingeniero en construcción y tiene sus aparatitos, llegó y le dijo al del palacio "¿sabes qué? tengo estos aparatos" y los aportó para que fueran a levantar escombros ( $\mathrm{Na}$ Irma).

La maquinaria especializada era necesaria y facilitaba el proceso de limpieza y levantamiento de escombros. Los restos del palacio municipal, del mercado, de las iglesias y de las escuelas fueron levantados primero. Sin embargo, los espacios familiares no se despejaron con rapidez. "El Ayuntamiento dijo que hasta que desocupáramos la calle iban a sacar el escombro, pero ¿cómo le hacíamos si vivíamos en la calle? Por eso se quedó mucho tiempo aquí. Para sacar el escombro cada uno conseguía las máquinas como podía" (Na Lugarda).

Pasaron meses para que las personas, con ayuda de las brigadas, pudieran sacar los restos de lo que un día habían sido sus hogares. Era común ver hombres manejando retroexcavadoras y volteos para dejar libres las calles, pero este trabajo se dificultaba porque los campamentos y las cocinas comunitarias estaban instaladas en medio de la vía pública. Poco a poco algunos sitios quedaron despejados, pero también hubo espacios en los que fue imposible limpiar debido a la insuficiencia de maquinaria o a la carencia de recursos para pagarla.

Además, una vez que los trabajos de limpieza estaban realizándose, ni las personas de la comunidad ni las autoridades sabían qué hacer con tantos escombros. La cantidad de ladrillos, adobe, tierra o concreto que sacaban era inimaginable y en Juchitán no había un sitio destinado a almacenar tantos restos de material. Para dar solución a este problema se ocuparon terrenos baldíos y los lugares más amplios que existían. "Los escombros los metieron en los ríos 0 en los lagos. Ocuparon las lagunas (...). Si hubieras pasado ahí verías que todo estaba lleno de escombros. El río estaba tapado. Y siguen derrumbando casas" apunta Heidi. 
Montañas de escombros podían observarse junto a los ríos y canales de Juchitán, en las canchas de futbol o en terrenos alejados del centro. Esos lugares se llenaron a más no poder y, aun así, el espacio fue insuficiente. Al no tener dónde colocar los restos que quedaban, las personas comenzaron a acumularlos a lo largo de las calles. Se esperaba que con el paso del tiempo las autoridades municipales encontraran una solución, pero no fue así. Aunque las brigadas ayudaron en gran medida a despejar espacios, las calles quedaron inundadas con ladrillos, piedras y vigas.

\section{A MODO DE CONCLUSIÓN}

Este trabajo reconstruye algunas experiencias alrededor del terremoto en Juchitán de Zaragoza y desarrolla las estrategias colectivas y las "luchas por lo común" (Navarro, 2015) que las personas desplegaron para cuidar, defender y reproducir la vida en el contexto del desastre. Las principales respuestas a las necesidades inmediatas que surgieron fueron: 1) salvar vidas y rescatar cuerpos; 2) conseguir comida y satisfacer el hambre; 3) crear un techo para resguardarse; 4) garantizar la seguridad y el cuidado mutuo; 5) levantar escombros y despejar espacios.

El análisis realizado abona tres contribuciones teóricas-metodológicas centrales. En primer lugar, muestra que ante el terremoto las acciones individuales o familiares no fueron suficientes para sostener la vida, mucho menos bastaron las escasas medidas emprendidas por el Estado y sus instituciones. En cambio, lo que posibilitó el sostén de la vida familiar y comunitaria fueron las diferentes estrategias colectivas que, basadas en los entramados comunitarios, las y los juchitecos activaron. "Todos salvaban a todos" decía Guie'biaani', pues los saberes, las experiencias, los afectos y las acciones particulares eran primordiales para la comunidad.

En segundo lugar, analizar los entramados comunitarios en contexto de desastre permite nutrir sectores académicos, sociales y gubernamentales, pues refleja que cuando la vida se muestra vulnerable y precaria diversas luchas por la búsqueda de bienestar brotan para satisfacer las necesidades y para crear y mejorar las condiciones vitales. La existencia de las personas no se sostiene en el vacío, en tiempos extraordinarios la interdependencia se hace visible y los entramados comunitarios se reavivan. Basados en la memoria y en experiencias organizativas previas, éstos toman fuerza y se hacen cuerpo colectivo para privilegiar el bien común. Pese a los vacíos de respuestas estatales inmediatas, las personas tienen la capacidad de organizarse, trabajar en conjunto y privilegiar el cuidado mutuo: reconocer esta potencia permite visibilizar que la población tiene múltiples herramientas para gestionar riesgos y disminuir la vulnerabilidad.

Finalmente, es necesario destacar la relevancia que el enfoque feminista tiene para analizar los impactos y la gestión de un desastre, pues ilumina las creativas respuestas y recursos de afrontamiento que despliegan las mujeres. Esta perspectiva permite desplazarlas del lugar de participantes vulnerables en que se les suele colocar para posicionarlas como sujetos de acción política que generan estrategias y dinámicas propias para reconstruir y sostener la vida. La organización, los trabajos y las relaciones que ellas crean, recrean y mantienen son un pilar central para reproducir la vida comunitaria.

\section{AGRADECIMIENTOS}

Agradezco a todas las mujeres juchitecas cuya voz nutre este texto, por mostrarme su mundo, sus saberes y sus sentires. Gracias por tanta fuerza para hacer la vida.

\section{REFERENCIAS}

Baez, Susann. (2017). La contribución de la Antropología al Estudio de Crisis y Desastres en América Latina. Iberoamericana-Nordic Journal of Latin American and Caribbean Studies, 46(1),1-5. https:// doi.org/10.16993/iberoamericana.102

Bessi, Renata, y Navarro, Santiago. (11 de octubre de 2017). México: Se aplica la doctrina del shock tras terremoto en Oaxaca. SubVersiones. Agencia Autónoma de Comunicación, págs. 1-15.

Castro, Cecilia, y Reyes, Luisa E. (2006). Desastres naturales y vulnerabilidad de las mujeres en México. Instituto Nacional de las Mujeres (INMUJERES) \& Programa de las Naciones Unidas para el Desarrollo (PNUD).

Federici, Silvia. (2013). Revolución punto cero. Trabajo doméstico, reproducción y luchas feministas. Traficantes de Sueños.

Ferri, Pablo. (1o de septiembre de 2017). Juchitán, el epicentro del dolor de México. El País. https:// elpais.com/internacional/2017/o9/o9/mexico/1504964259_368937.html 
García, Norlang, Méndez, Karla, Franco, Ernesto, y Olmedo, Cristina. (2019). 2017. Impacto socioeconómico de los principales desastres ocurridos en la República Mexicana. Secretaría de seguridad y Protección Ciudadana y Centro Nacional de Prevención de Desastres.

Guber, Rosana. (2001). La etnografía: método, campo y reflexividad. Grupo Editorial Norma.

Gutiérrez, Raquel. (2008). Los ritmos del Pachakuti. Movilización y levantamiento popular-indígena en Bolivia (2000-2005). Tinta Limón.

Gutiérrez, Raquel. (2013). Conocer las luchas y desde las luchas. Reflexiones sobre el despliegue polimorfo del antagonismo: entramados comunitarios y horizontes políticos. Acta Sociológica, 62, 11-30. https://doi.org/10.1016/So186-6028(13)70997-6

Gutiérrez, Raquel. (2017). Producir lo común: entramados comunitarios y formas de lo político. Traficantes de Sueños.

Gutiérrez, Raquel, Navarro, Mina, y Linsalata, Lucía. (2016). Repensar lo político, pensar lo común. Claves para la discusión. En L. Linsalata, D. Inclán, y M. Millán (Eds.), Modernidades Alternativas y nuevo sentido común: ¿hacia una modernidad no capitalista? (págs. 377-417). Facultad de Ciencias Políticas y Sociales-UNAM.

Haraway, Donna. (1995). Conocimientos situados: la cuestión científica en el feminismo y el privilegio de la perspectiva parcial. En D. Haraway (Ed.), Ciencia, ciborgs y mujeres. La reinvención de la naturaleza (págs. 313-146). Cátedra.

Harding, Sandra. (1998). ¿Existe un método feminista? En E. Bartra (Ed.), Debates en torno a una metodología feminista (págs. 9-34). Universidad Autónoma Metropolitana.

Juárez-Acevedo, Itandehui. (2020). Cocinas comunitarias en Juchitán de Zaragoza: el trabajo de las mujeres en la base de la vida. Cuadernos del Sur, (49), 87-106. https://cuadernosdelsur.com/ revistas/49-\%ez\%80\%az-julio-diciembre-2020/

Martín Beristain, Carlos. (200o). Apoyo psicosocial en catástrofes colectivas: de la prevención a la reconstrucción. Universidad Central de Venezuela y Asociación venezolana de Psicología Social (AVEPSO).

Martínez Luna, Jaime. (2010). Eso que llaman comunalidad. Culturas Populares, CONACULTA, Secretaría de la Cultura-Gobierno de Oaxaca \& Fundación Alfredo Harp Helú Oaxaca A.C.

Martínez Luna, Jaime. (2015). Conocimiento y comunalidad. Bajo el Volcán, 15(23), 99-112. http://www. redalyc.org/articulo.oa?id=28643473006

Massolo, Alejandra. (1986). ¡Que el gobierno entienda, lo primero es la vivienda! La organización de los damnificados. Revista Mexicana de Sociología (2), 195-238. https://doi.org/10.2307/3540362

Milenio. (11 de septiembre de 2017). En Oaxaca, sismo ha dejado 76 muertos y al menos 12 mil casas dañadas. Milenio. https://www.milenio.com/estados/ oaxaca-sismo-dejado-76-muertos-12-mil-casas-danadas

Navarro, Mina. (2015). Hacer común contra la fragmentación en la ciudad: experiencias de autonomía para la reproducción de la vida. El Apantle. Revista de estudios comunitarios, (1), 99-124.

Oficina del Coordinador Residente de las Naciones Unidas. (2017). México: Sismo 8.2 grados Richter. Reporte de Situación No. o1. Sistema de las Naciones Unidad. https://www.paho.org/disasters/ dmdocuments/Sismo\%2oMEX-Sitrep\%201\%20ONU\%20-\%2013SET2017.pdf

Pérez, Alonso. (9 de septiembre de 2017). La falta de servicios médicos exhibe la crisis de Juchitán. El Imparcial del Istmo. http://imparcialoaxaca.mx/istmo/55054/ la-falta-de-servicios-medicos-exhibe-la-crisis-de-juchitan/

Reguillo, Rossana. (2005). La construcción simbólica de la ciudad. Sociedad, desastre y comunicación. Instituto Tecnológico y de Estudios Superiores de Occidente (ITESO) \& Universidad Iberoamericana A.C.

Restrepo, Eduardo. (2007). La entrevista como técnica de investigación social: Notas para los jóvenes investigadores. Universidad ICESI/ Facultad de Derecho y Ciencias Sociales.

Rockwell, Elsie. (2019). La experiencia etnográfica. Paidós.

Tamayo, Sergio. (2006). Espacios de ciudadanía, espacios de conflicto. Sociológica (61), 11-40.

UNICEF. (2018). Informe sobre la situación humanitaria de la infancia y la adolescencia a un año de los teremotos en Méxio. Fondo de las Naciones Unidas para la Infancia (UNICEF). 